\title{
Utility of intraoperative rotational thromboelastometry in thoracolumbar deformity surgery
}

\author{
Jian Guan, MD, ${ }^{1}$ Chad D. Cole, MD, MSc, ${ }^{1}$ Meic H. Schmidt, MD, MBA, ${ }^{1,2}$ and Andrew T. Dailey, MD1 \\ 1Department of Neurosurgery, Clinical Neurosciences Center, University of Utah, Salt Lake City, Utah; and 2Department of \\ Neurosurgery, Westchester Medical Center, Valhalla, New York
}

\begin{abstract}
OBJECTIVE Blood loss during surgery for thoracolumbar scoliosis often requires blood product transfusion. Rotational thromboelastometry (ROTEM) has enabled the more targeted treatment of coagulopathy, but its use in deformity surgery has received limited study. The authors investigated whether the use of ROTEM reduces transfusion requirements in this case-control study of thoracolumbar deformity surgery.

METHODS Data were prospectively collected on all patients who received ROTEM-guided blood product management during long-segment ( $\geq 7$ levels) posterior thoracolumbar fusion procedures at a single institution from April 2015 to February 2016. Patients were matched with a group of historical controls who did not receive ROTEM-guided therapy according to age, fusion segments, number of osteotomies, and number of interbody fusion levels. Demographic, intraoperative, and postoperative transfusion requirements were collected on all patients. Univariate analysis of ROTEM status and multiple linear regression analysis of the factors associated with total in-hospital transfusion volume were performed, with $p<0.05$ considered to indicate statistical significance.
\end{abstract}

RESULTS Fifteen patients who received ROTEM-guided therapy were identified and matched with 15 non-ROTEM controls. The mean number of fusion levels was 11 among all patients, with no significant differences between groups in terms of fusion levels, osteotomy levels, interbody fusion levels, or other demographic factors. Patients in the nonROTEM group required significantly more total blood products during their hospitalization than patients in the ROTEM group (8.5 \pm 4.2 units vs $3.71 \pm 2.8$ units; $p=0.001$ ). Multiple linear regression analysis showed that the use of ROTEM $(p=0.016)$ and a lower number of fused levels $(p=0.022)$ were associated with lower in-hospital transfusion volumes. CONCLUSIONS ROTEM use during thoracolumbar deformity correction is associated with lower transfusion requirements. Further investigation will better define the role of ROTEM in transfusion during deformity surgery.

https://thejns.org/doi/abs/10.3171/2017.5.SPINE1788

KEY WORDS rotational thromboelastometry; spine surgery; thoracolumbar deformity; blood product management; blood transfusion; coagulation testing

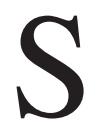
PINAL deformity surgery is often associated with a significant volume of blood loss. ${ }^{2,7}$ The need for blood transfusion to compensate for these losses is associated with a wide array of complications, including infection, ${ }^{11}$ thromboembolic events, ${ }^{1}$ and hemolytic reactions. ${ }^{17}$ In addition, patients requiring blood transfusion have been shown to have prolonged hospitalizations and higher surgery-related costs. ${ }^{23}$ Because of these myriad deleterious effects, significant efforts have been made to curtail the need for blood products intraoperatively and perioperatively. ${ }^{3,4}$

Rotational thromboelastometry (ROTEM; TEM International $\mathrm{GmbH}$ ) is a form of viscoelastic testing that allows rapid analysis of multiple coagulation parameters. ${ }^{6} \mathrm{Al}-$ though significant questions remain regarding the interpretation and standardization of ROTEM,${ }^{10}$ trauma and transplant surgeons have begun to use this technology in clinical practice to guide transfusion and improve outcomes. ${ }^{15,16,21}$

ABBREVIATIONS BMI = body mass index; FFP = fresh-frozen plasma; INR = international normalized ratio; PRBC = packed red blood cell; ROTEM = rotational thromboelastometry; TXA = tranexamic acid.

SUBMITTED January 20, 2017. ACCEPTED May 12, 2017.

INCLUDE WHEN CITING Published online September 1, 2017; DOI: 10.3171/2017.5.SPINE1788. 


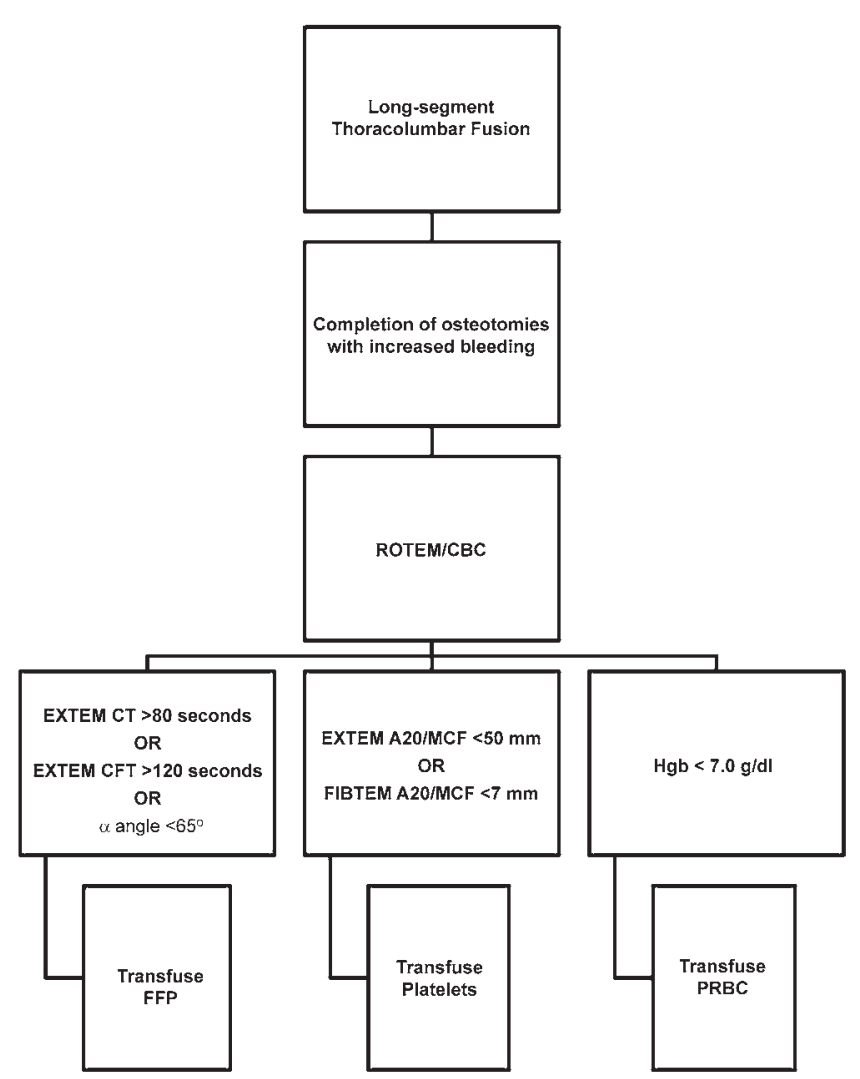

FIG. 1. ROTEM transfusion protocol. $A 20$ = clot firmness after 20 minutes of clot formation; $\mathrm{CBC}=$ complete blood count; $\mathrm{CFT}=$ clot formation time; $\mathrm{CT}=$ clotting time; $\mathrm{Hgb}=$ hemoglobin; $\mathrm{MCF}=$ mean clot firmness; $P O C=$ point of care.

Investigations into the use of ROTEM for spine surgery (in general) and for deformity surgery (in particular) remain extremely limited. In this study, we investigated the use of ROTEM-guided transfusion in long-segment $(\geq 7$ levels) thoracolumbar fusions for adult deformity. We hypothesized that the use of ROTEM during surgery would reduce intraoperative and postoperative blood transfusion requirements.

\section{Methods}

\section{Study Population}

After obtaining approval from the institutional review board, we retrospectively reviewed a prospectively collected database to identify patients who underwent single-stage posterior thoracolumbar instrumented fusion procedures at our institution from April 1, 2015, to February 1,2016. All patients undergoing fusions of 7 or more segments during this period who had ROTEM-guided intraoperative blood management were identified (Fig. 1). These patients were then matched based on age, surgical levels, osteotomy levels, interbody fusion levels, tranexamic acid (TXA) use, and revision status with historical controls operated on between March 1, 2012, and March 1, 2016, who had intraoperative blood management without ROTEM guidance (Fig. 2). All included ROTEM-guided operations were performed sequentially

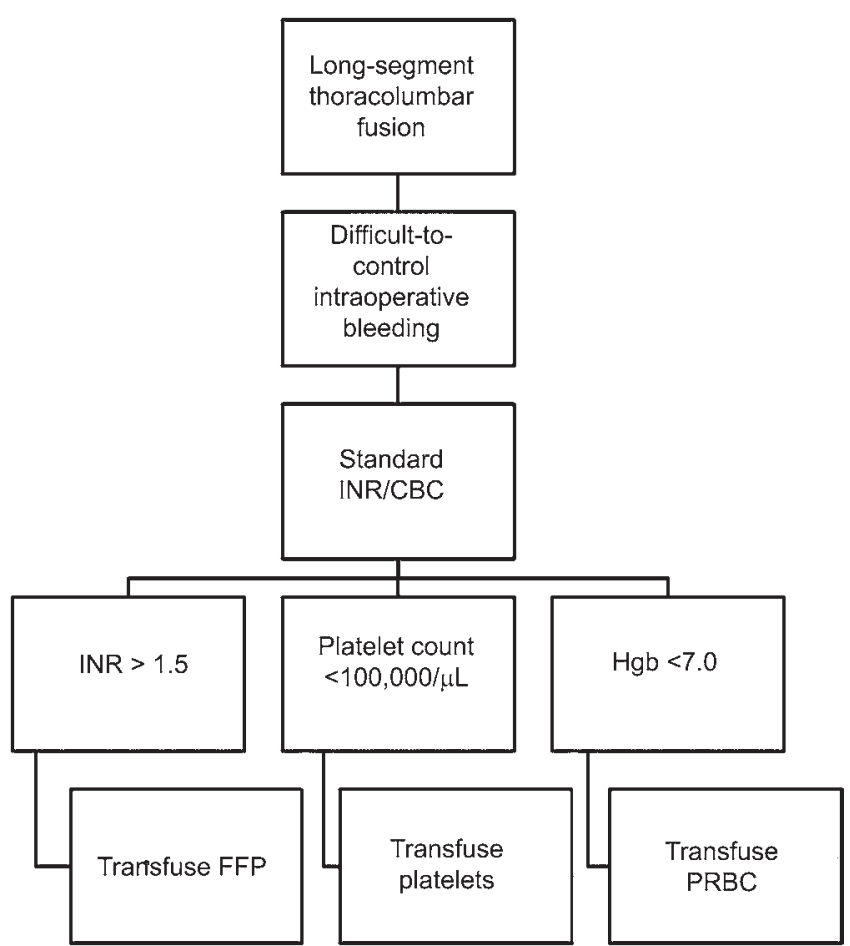

FIG. 2. Non-ROTEM transfusion protocol.

over the study period with a single exception: 1 control case was performed during the ROTEM time frame because the ROTEM machine was not available when the surgery was being performed. Non-ROTEM procedures were not necessarily performed sequentially, as they were selected from cases performed during the study period based on our matching criteria.

A single experienced surgeon (A.T.D.) performed all surgical procedures, and all surgeries were performed with the assistance of a specialized neuroanesthesiology team. Transfusion guidelines (Figs. 1 and 2) were adhered to whenever possible, and any deviations were the result of discussions between the neurosurgeon and anesthesiologist based on the available data.

\section{Data Collection}

Preoperative data including age, sex, body mass index (BMI), preoperative hematocrit, preoperative platelet count, preoperative international normalized ratio (INR), and American Society of Anesthesiologists Physical Status Classification System grade were collected for all patients. Surgical data included whether the surgery was a revision, the number of levels fused, the number of osteotomy levels performed (pedicle subtraction, SmithPetersen, or vertebral column resection), and the number of interbody fusions performed. Intraoperative variables included the total number of units of packed red blood cells (PRBCs), platelets, and fresh-frozen plasma (FFP) that were transfused during the procedure. The volume of autologous blood transfused was also recorded and converted to units according to the standard volume of 1 unit of PRBCs at our institution (1 unit of PRBCs $=250$ $\mathrm{ml}$ blood). We also determined the estimated intraopera- 
tive blood loss and amount of crystalloid/colloid solution infused. TXA was used in select cases at the discretion of the attending surgeon and anesthesiologist when significant blood loss was expected, and the use of TXA was recorded for each case. Data on cell-saver use for autologous blood transfusion for each case were also collected, as were operative duration and the percentage of surgery during which the patient was hypothermic (defined as body temperature $<36^{\circ} \mathrm{C}$ ). ${ }^{8}$

Postoperative variables included length of stay, drain output, postoperative hematocrit, postoperative platelet count, postoperative INR, and the number of postoperative PRBCs, platelets, and FFP units transfused during the remainder of the patient's hospitalization. The total amount of blood products used in each patient during hospitalization, which consisted of the total number of units of PRBCs, platelets, FFP, and autologous blood transfused intraoperatively and postoperatively, was also calculated. ROTEM data were collected after the placement of all pedicle screws and completion of the osteotomies, as well as during the final correction of the deformity through the placement of rods.

\section{Statistical Analysis}

Continuous variables were analyzed using the Student t-test, and categorical variables were analyzed using the chi-square test. Univariate analysis was performed to compare total in-hospital blood transfusion volumes between ROTEM and non-ROTEM patients. Multiple linear regression analysis was then performed to compare the 2 groups. Variables were selected for this model if we thought they would significantly impact transfusion volume. These variables included ROTEM use, number of levels fused, preoperative hematocrit, preoperative INR, and TXA use. In all analyses, $\mathrm{p}<0.05$ was considered statistically significant. The statistical analysis was performed using SPSS (version 20.0; IBM Corp.).

\section{Results}

Fifteen patients who received ROTEM-guided therapy and met the inclusion criteria were identified and matched with 15 non-ROTEM control patients. Our matched variables were not significantly different between the ROTEM and non-ROTEM groups, with similar ages, sex distributions, BMIs, fusion levels, osteotomy levels, interbody levels, revision rates, and TXA use rates in the 2 groups (Table 1). Preoperative and postoperative laboratory values were also similar in the groups. Patients in the nonROTEM group received significantly higher volumes of PRBCs, FFP, and autologous blood transfusions intraoperatively compared with patients in the ROTEM group. Blood loss appeared to be greater in the non-ROTEM group, although this difference did not reach statistical significance. Postoperative blood transfusion requirements were similarly low in both groups. Total blood products transfused during hospitalization were significantly higher in the non-ROTEM group than in the ROTEM group. Of note, although we used mean values for our calculations, the median values for total blood transfusion were also significantly different between the 2 groups when ana-
TABLE 1. Univariate analysis of ROTEM versus non-ROTEM groups

\begin{tabular}{|c|c|c|c|}
\hline Characteristic & Non-ROTEM & ROTEM & $\begin{array}{c}\mathrm{p} \\
\text { Value }\end{array}$ \\
\hline No. of patients & 15 & 15 & \\
\hline Female, no. (\%) & $7(47)$ & $10(67)$ & 0.269 \\
\hline Age, yrs & $65.6 \pm 12.7$ & $61.9 \pm 11.1$ & 0.400 \\
\hline $\mathrm{BMI}, \mathrm{kg} / \mathrm{m}^{2}$ & $28.8 \pm 4.6$ & $27.7 \pm 6.1$ & 0.578 \\
\hline ASA PS grade, no. (\%) & & & 0.275 \\
\hline II & $5(33)$ & $4(27)$ & \\
\hline III & $8(53)$ & $11(73)$ & \\
\hline IV & $2(13)$ & $0(0)$ & \\
\hline Preop hematocrit, $\%$ & $39.0 \pm 6.0$ & $40.8 \pm 5.9$ & 0.410 \\
\hline Preop platelet count, platelets/ $\mu$ l & $245.7 \pm 54.4$ & $256.2 \pm 96.0$ & 0.718 \\
\hline Preop INR & $1.10 \pm 0.17$ & $1.02 \pm 0.06$ & 0.114 \\
\hline Levels fused & $11.5 \pm 3.3$ & $10.3 \pm 3.2$ & 0.317 \\
\hline Osteotomy levels & $1.9 \pm 2.0$ & $2.3 \pm 3.0$ & 0.617 \\
\hline Interbody levels & $0.20 \pm 0.41$ & $0.33 \pm 0.62$ & 0.493 \\
\hline Intraop PRBC, units & $2.6 \pm 2.0$ & $0.93 \pm 1.5$ & 0.016 \\
\hline Intraop autologous blood, units & $2.1 \pm 1.0$ & $0.97 \pm 1.3$ & 0.009 \\
\hline Intraop platelets, units & $0.40 \pm 1.06$ & $0.07 \pm 0.26$ & 0.245 \\
\hline Intraop FFP, units & $2.0 \pm 1.7$ & $0.53 \pm 1.0$ & 0.007 \\
\hline Estimated blood loss, ml & $1880 \pm 700$ & $1347 \pm 857$ & 0.072 \\
\hline Crystalloid volume, ml & $4606 \pm 1890$ & $5310 \pm 1918$ & 0.320 \\
\hline Colloid volume, $\mathrm{ml}$ & $633 \pm 581$ & $800 \pm 649$ & 0.465 \\
\hline TXA use, no. (\%) & $3(20)$ & $3(20)$ & 1.000 \\
\hline Cell-saver use, no. (\%) & $13(87)$ & $10(67)$ & 0.195 \\
\hline Op time, mins & $510.7 \pm 118.1$ & $484.7 \pm 77.9$ & 0.482 \\
\hline Op time spent hypothermic, $\%$ & $36.8 \pm 31.4$ & $38.4 \pm 25.2$ & 0.881 \\
\hline Length of stay, days & $10.7 \pm 5.1$ & $8.2 \pm 2.7$ & 0.099 \\
\hline Drain output, ml & $1508 \pm 786$ & $1392 \pm 454$ & 0.480 \\
\hline Postop PRBC, units & $1.1 \pm 1.4$ & $1.1 \pm 0.9$ & 0.881 \\
\hline Postop platelets, units & $0.27 \pm 0.70$ & $0.07 \pm 0.26$ & 0.310 \\
\hline Postop FFP, units & 0 & 0 & NA \\
\hline Postop hematocrit, \% & $28.8 \pm 3.1$ & $28.0 \pm 3.9$ & 0.575 \\
\hline $\begin{array}{l}\text { Postop platelet count, platelets/ } \\
\mu \mathrm{l}\end{array}$ & $175.3 \pm 78.6$ & $185.5 \pm 69.4$ & 0.707 \\
\hline Postop INR & $1.31 \pm 0.18$ & $1.34 \pm 0.11$ & 0.706 \\
\hline $\begin{array}{l}\text { Total blood products transfused, } \\
\text { units }\end{array}$ & $8.45 \pm 4.2$ & $3.71 \pm 2.75$ & 0.001 \\
\hline
\end{tabular}

ASA PS = American Society of Anesthesiologists Physical Status; NA = not applicable.

Values are presented as the mean \pm SD unless specified otherwise. Boldface type indicates statistical significance.

lyzed using the Mann-Whitney U-test (median 3.6 units [interquartile range $2-4.8$ units] for the ROTEM group vs 8.0 units [interquartile range 3.6-11.2 units] for the nonROTEM group; $\mathrm{p}=0.0035$ ).

There were no significant differences in the rates of cell-saver use $(p=0.195)$ or operative duration $(p=0.482)$ between the 2 groups. The percentage of time spent with a temperature less than $36^{\circ} \mathrm{C}$ was not significantly different when comparing the ROTEM group with the non- 
TABLE 2. Multiple linear regression analysis of total blood transfusion volume

\begin{tabular}{lrrcc}
\hline \multicolumn{1}{c}{ Characteristic } & \multicolumn{1}{c}{ Beta } & \multicolumn{1}{c}{ B } & $95 \%$ Cl for B & $p$ Value \\
\hline ROTEM use & -0.487 & -3.973 & -7.109 to -0.838 & $\mathbf{0 . 0 1 6}$ \\
\hline Levels fused & 0.408 & 0.501 & 0.022 to -0.981 & $\mathbf{0 . 0 2 2}$ \\
\hline Preop hematocrit & 0.086 & 0.060 & -0.200 to 0.321 & 0.633 \\
\hline Preop INR & 0.103 & 3.485 & -9.324 to 16.294 & 0.576 \\
\hline TXA use & -0.304 & -2.883 & -6.425 to 0.658 & 0.105 \\
\hline
\end{tabular}

Boldface type indicates statistical significance.

ROTEM group $(38.4 \% \pm 25.2 \%$ vs $36.8 \% \pm 31.4 \%$; $\mathrm{p}=$ $0.881)$.

In our multiple linear regression model, only ROTEM use and number of levels fused remained significantly associated with an increase in total in-hospital transfusion (Table 2). According to the results of our multiple linear regression analysis, the incorporation of ROTEM-guided transfusion management decreased a patient's total inhospital transfusion requirement by nearly 4 units $(95 \%$ CI 0.8-7.1).

Examples of normal EXTEM (the measure of the extrinsic hemostatic system within ROTEM) (Fig. 3 upper) and FIBTEM (the measure of the platelet contribution to the clot within ROTEM) (Fig. 3 lower) readouts (subsections of the ROTEM study) are shown: this patient received no intraoperative blood products. Similarly, examples of abnormal EXTEM (Fig. 4 upper) and borderline FIBTEM (Fig. 4 lower) are provided, and this patient required intraoperative transfusion of FFP.

\section{Discussion}

With the progressively increasing number and com- plexity of spinal surgeries performed, intraoperative blood loss has rapidly become a dilemma for both surgeons and anesthesiologists. In the adult deformity population, in whom older age can be associated with multiple risk factors for increased bleeding such as a thinner periosteum, wider vascular channels secondary to osteoporosis, and stiffer spinal columns that require more extensive osteotomies, ${ }^{9}$ this concern is further magnified. Reports of typical blood loss during posterior deformity procedures vary, with a range in the literature of $<1 \mathrm{~L}$ to nearly $5 \mathrm{~L}, 5,13,14$ representing between $<20 \%$ and nearly $100 \%$ of a typical adult's circulating blood volume being replaced. ${ }^{25}$

Viscoelastic testing such as ROTEM is gaining increasing traction in a variety of surgical fields because of its relatively low cost, rapid turnaround time, and ability to offer a more nuanced picture of coagulopathy. ${ }^{18,22,24}$ Naik et al. ${ }^{20}$ recently published their series examining the use of ROTEM in the deformity population, and to date that paper constitutes the entire body of literature investigating the use of ROTEM in complex spine surgery. They found that a reduction in blood loss was achieved in patients who received ROTEM-guided therapy, possibly leading to a reduction in overall cost. Although our study examines a modestly different patient group-thoracolumbar deformity patients who had fusions more than 7 levels in length and with fewer revision surgeries-our findings appear to support theirs.

Patients in our cohort who received ROTEM-guided blood transfusion management had significantly lower in-hospital blood transfusion needs. One possible explanation for this difference is the use of a more targeted or timely transfusion of blood products in the ROTEM group compared with the non-ROTEM group. For example, a patient who had ROTEM-guided therapy may have received FFP in the early stages of coagulopathy, whereas a patient in the non-ROTEM group might have received FFP only after a large volume of blood was lost and hemo-

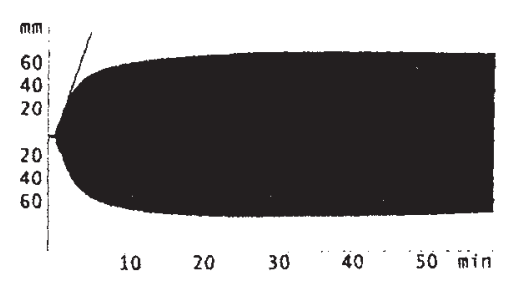

\begin{tabular}{|c|c|c|c|c|c|}
\hline & $\begin{array}{l}\text { EXTEM } \\
1: 4333373\end{array}$ & & & 2: & \\
\hline RT: & $01: 00: 20$ & & ST: & $2016-01-1$ & $11 \tau 17: 09: 28$ \\
\hline$C T$ & : & 65 & 5 & 43 & $82]$ \\
\hline CFT & : & 55 & $s$ & 48 & $127 \mathrm{~J}$ \\
\hline$\alpha$ & : & 79 & 。 & 65 & $80]$ \\
\hline A10 & : & 64 & $\mathrm{~mm}$ & & \\
\hline$A 20$ & : & 69 & $\mathrm{~mm}$ & 50 & $70]$ \\
\hline MCF & : & 70 & $\mathrm{~mm}$ & 52 & $70]$ \\
\hline ML & * & 3 & $\%$ & & \\
\hline
\end{tabular}

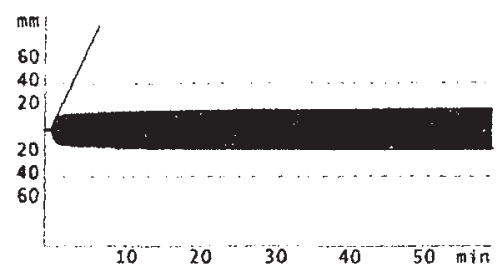

\begin{tabular}{|c|c|c|c|c|c|c|c|}
\hline 3 & $\begin{array}{l}\text { FIBTEM } \\
1: 4333373\end{array}$ & & \multicolumn{5}{|c|}{ 2: } \\
\hline RT: & $01: 00: 18$ & & st: & 2016 & $01-1$ & 1T17: & $: 11: 24$ \\
\hline CT & : & 56 & s & & & & \\
\hline CFT & : & & s & & & & \\
\hline$\alpha$ & : & 74 & 。 & & & & \\
\hline A10 & : & 16 & $\mathrm{~mm}$ & & & & \\
\hline$A 20$ & : & 17 & $\mathrm{~mm}$ & {[} & 7 & - & 24] \\
\hline MCF & : & 18 & $\mathrm{~mm}$ & {[} & 7 & - & 24] \\
\hline$M L$ & : * & 0 & $\%$ & & & & \\
\hline
\end{tabular}

FIG. 3. Upper: Example of a normal EXTEM readout that indicates no intervention is needed in this patient. Lower: Example of a normal FIBTEM readout that indicates no intervention is needed in this patient. $M L=$ maximum lysis. 


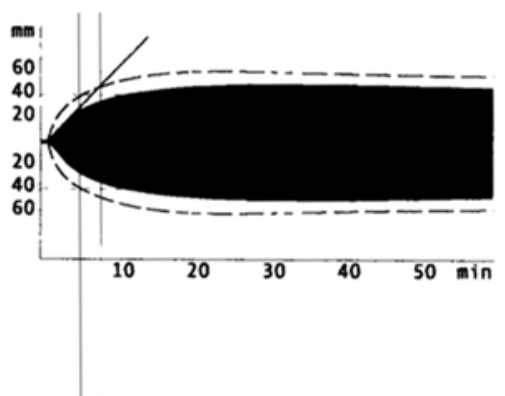

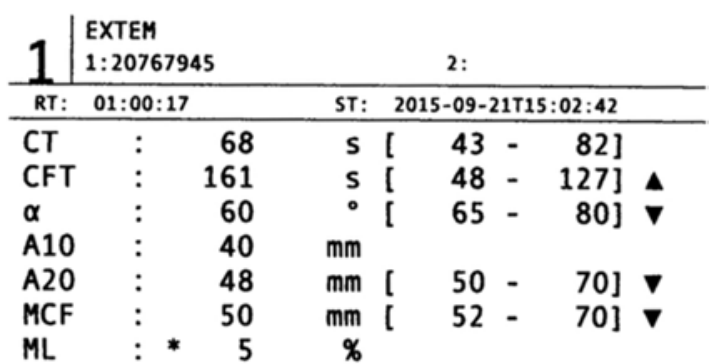

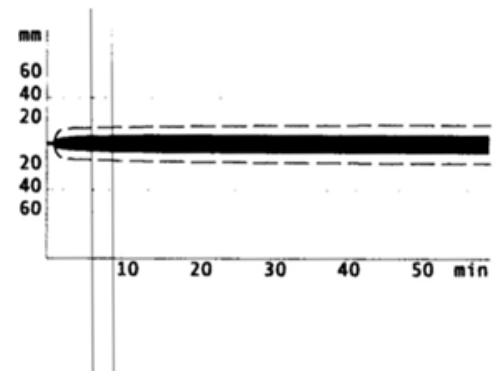

\begin{tabular}{|c|c|c|c|c|c|}
\hline 3 & $\begin{array}{l}\text { FIBTEM } \\
1: 20767945\end{array}$ & & & 2: & \\
\hline RT: & $01: 00: 18$ & & ST: & 2015-09-21T15: & $04: 29$ \\
\hline CT & : & 59 & $\mathbf{s}$ & & \\
\hline CFT & : & & $\mathbf{s}$ & & \\
\hline$\alpha$ & : & & - & & \\
\hline A10 & : & 8 & $\mathrm{~mm}$ & & \\
\hline A20 & : & 8 & $\mathrm{~mm}$ & $7-$ & 24] \\
\hline MCF & : & 8 & $\mathrm{~mm}$ & $7-$ & 24] \\
\hline ML & : * & 1 & $\%$ & & \\
\hline
\end{tabular}

FIG. 4. Upper: Example of an abnormal EXTEM readout that would prompt transfusion of FFP in this patient. Lower: Example of a borderline FIBTEM readout that might prompt transfusion of FFP in this patient.

static derangement had worsened. This may also explain the trend toward lower overall intraoperative blood loss in our ROTEM cohort. Another explanation could be a reduction in the use of preemptive blood transfusion, which is possible because knowledge of a patient's coagulation profile allows better prediction of a patient's transfusion needs and reduces overtransfusion. As can be seen in the differences in the transfusion algorithms between our study and that described by Naik et al., one of the major challenges in the utilization of ROTEM is disagreement in the timing and interpretation of the results, a fact that was also highlighted in a recent Cochrane review. ${ }^{10}$ This is further complicated by the relative unfamiliarity of many practitioners in the use of ROTEM.

The reduction in blood transfusion and minimization of blood loss during spinal deformity surgeries is of vital importance for several reasons. High-volume transfusions increase patient risk for various adverse events, including infection, cardiac and renal dysfunction, and transfusionrelated acute lung injury. ${ }^{9}$ Higher intraoperative blood loss is also associated with the dreaded complication of postoperative visual loss due to ischemic optic neuropathy. ${ }^{12}$ From a socioeconomic standpoint, blood transfusions after spinal fusions are also associated with prolonged intensive care stays ${ }^{19}$ and longer hospitalizations overall. ${ }^{26}$ Length of stay in the ROTEM group was slightly shorter, although not significantly so, possibly because of the known impacts of higher transfusion needs. ${ }^{23}$

Our study has several limitations, the foremost of which are its retrospective nature and small sample size which increase its vulnerability to confounding factors such as non-ROTEM-related changes in technique or transfusion patterns that could influence transfusion use. The small number of patients also limits the power of our study. This may help to explain the fact that while there was a trend toward decreased blood loss in our ROTEM group compared with our non-ROTEM cohort (on average $>500 \mathrm{ml}$ less in the former compared with the latter), this difference did not reach statistical significance. Although a single surgeon performed all procedures and we limited our control cohort to a 4-year period, it is possible that changes in surgical technique or anesthesia staffing may have influenced transfusion practices. Because of the lack of data on the timing of blood transfusions during surgery in relation to the laboratory results, our study is unable to make definitive conclusions about how ROTEM influenced transfusion practices on a more granular level, although the majority of transfusions in our cohort occurred after correction of deformity. Future studies on this topic would likely benefit from the precise recording of both the time and stage of surgery during which the laboratory values are determined and transfusions occur, as well as the precise decision-making response to each laboratory value. Our study represents a limited initial study of the possible benefits of ROTEM use in long-segment thoracolumbar fusion for deformity. Further studies-preferably prospective, randomized controlled trials with multiple centers-are needed to better define the usefulness of ROTEM in deformity surgery and elucidate the optimal response to the results of ROTEM testing.

\section{Conclusions}

In long-segment posterior spinal fusion for deformity correction, the utilization of ROTEM-guided transfusion management may be associated with decreased in-hospital transfusion requirements. Our results suggest that further research is merited on the utility of ROTEM in this population (in particular) and spine surgery (in general). An additional goal of future research should be to better standardize the interpretation of ROTEM results. 


\section{References}

1. Basques BA, Anandasivam NS, Webb ML, Samuel AM, Lukasiewicz AM, Bohl DD, et al: Risk factors for blood transfusion with primary posterior lumbar fusion. Spine (Phila Pa 1976) 40:1792-1797, 2015

2. Carabini LM, Zeeni C, Moreland NC, Gould RW, Avram MJ, Hemmer LB, et al: Development and validation of a generalizable model for predicting major transfusion during spine fusion surgery. J Neurosurg Anesthesiol 26:205-215, 2014

3. Cardone D, Klein AA: Perioperative blood conservation. Eur J Anaesthesiol 26:722-729, 2009

4. Clevenger B, Mallett SV, Klein AA, Richards T: Patient blood management to reduce surgical risk. Br J Surg 102:1324-1337, 2015

5. Dorward IG, Lenke LG, Stoker GE, Cho W, Koester LA, Sides BA: Radiographic and clinical outcomes of posterior column osteotomies in spinal deformity correction. Spine (Phila Pa 1976) 39:870-880, 2014

6. Hans GA, Besser MW: The place of viscoelastic testing in clinical practice. Br J Haematol 173:37-48, 2016

7. Hart RA, Cabalo A, Bess S, Akbarnia BA, Boachie-Adjei O, Burton D, et al: Comparison of patient and surgeon perceptions of adverse events after adult spinal deformity surgery. Spine (Phila Pa 1976) 38:732-736, 2013

8. Hart SR, Bordes B, Hart J, Corsino D, Harmon D: Unintended perioperative hypothermia. Ochsner J 11:259-270, 2011

9. Hu SS: Blood loss in adult spinal surgery. Eur Spine J 13 (Suppl 1):S3-S5, 2004

10. Hunt H, Stanworth S, Curry N, Woolley T, Cooper C, Ukoumunne $\mathrm{O}$, et al: Thromboelastography (TEG) and rotational thromboelastometry (ROTEM) for trauma induced coagulopathy in adult trauma patients with bleeding. Cochrane Database Syst Rev (2):CD010438, 2015

11. Kato S, Chikuda H, Ohya J, Oichi T, Matsui H, Fushimi K, et al: Risk of infectious complications associated with blood transfusion in elective spinal surgery-a propensity score matched analysis. Spine J 16:55-60, 2016

12. Kla KM, Lee LA: Perioperative visual loss. Best Pract Res Clin Anaesthesiol 30:69-77, 2016

13. Kleinstueck FS, Fekete TF, Jeszenszky D, Haschtmann D, Mannion AF: Adult degenerative scoliosis: comparison of patient-rated outcome after three different surgical treatments. Eur Spine J 25:2649-2656, 2016

14. Lagrone MO, Bradford DS, Moe JH, Lonstein JE, Winter RB, Ogilvie JW: Treatment of symptomatic flatback after spinal fusion. J Bone Joint Surg Am 70:569-580, 1988

15. Mace H, Lightfoot N, McCluskey S, Selby R, Roy D, Timoumi T, et al: Validity of thromboelastometry for rapid assessment of fibrinogen levels in heparinized samples during cardiac surgery: a retrospective, single-center, observational study. J Cardiothorac Vasc Anesth 30:90-95, 2016

16. Mallett SV: Clinical utility of viscoelastic tests of coagulation (TEG/ROTEM) in patients with liver disease and during liver transplantation. Semin Thromb Hemost 41:527-537, 2015

17. Minhas SV, Chow I, Bosco J, Otsuka NY: Assessing the rates, predictors, and complications of blood transfusion volume in posterior arthrodesis for adolescent idiopathic scoliosis. Spine (Phila Pa 1976) 40:1422-1430, 2015
18. Na HS, Shin HJ, Lee YJ, Kim JH, Koo KH, Do SH: The effect of tranexamic acid on blood coagulation in total hip replacement arthroplasty: rotational thromboelastographic $\left(\right.$ ROTEM $\left.^{\circledR}\right)$ analysis. Anaesthesia 71:67-75, 2016

19. Nahtomi-Shick O, Kostuik JP, Winters BD, Breder CD, Sieber AN, Sieber FE: Does intraoperative fluid management in spine surgery predict intensive care unit length of stay? J Clin Anesth 13:208-212, 2001

20. Naik BI, Pajewski TN, Bogdonoff DI, Zuo Z, Clark P, Terkawi AS, et al: Rotational thromboelastometry-guided blood product management in major spine surgery. J Neurosurg Spine 23:239-249, 2015

21. Nguyen TT, Hill S, Austin TM, Whitney GM, Wellons JC III, Lam HV: Use of blood-sparing surgical techniques and transfusion algorithms: association with decreased blood administration in children undergoing primary open craniosynostosis repair. J Neurosurg Pediatr 16:1-8, 2015

22. Sangkhathat S, Suwannarat D, Boonpipattanapong T, Sangthong B: Rotational thromboelastometry in the diagnosis of coagulopathy in major pediatric surgical operations. J Pediatr Surg 50:2001-2004, 2015

23. Seicean A, Alan N, Seicean S, Neuhauser D, Weil RJ: The effect of blood transfusion on short-term, perioperative outcomes in elective spine surgery. J Clin Neurosci 21:15791585,2014

24. Whiting P, Al M, Westwood M, Ramos IC, Ryder S, Armstrong N, et al: Viscoelastic point-of-care testing to assist with the diagnosis, management and monitoring of haemostasis: a systematic review and cost-effectiveness analysis. Health Technol Assess 19:1-228, v-vi, 2015

25. Yu M, Pei K, Moran S, Edwards KD, Domingo S, Steinemann S, et al: A prospective randomized trial using blood volume analysis in addition to pulmonary artery catheter, compared with pulmonary artery catheter alone, to guide shock resuscitation in critically ill surgical patients. Shock 35:220-228, 2011

26. Zheng F, Cammisa FP Jr, Sandhu HS, Girardi FP, Khan SN: Factors predicting hospital stay, operative time, blood loss, and transfusion in patients undergoing revision posterior lumbar spine decompression, fusion, and segmental instrumentation. Spine (Phila Pa 1976) 27:818-824, 2002

\section{Disclosures}

Dr. Dailey reports being a consultant for K2M and Zimmer/ Biomet and receiving non-study-related clinical or research support from K2M.

\section{Author Contributions}

Conception and design: all authors. Acquisition of data: Guan. Drafting the article: Dailey, Guan. Critically revising the article: Dailey. Reviewed submitted version of manuscript: Dailey, Guan. Approved the final version of the manuscript on behalf of all authors: Dailey.

\section{Correspondence}

Andrew T. Dailey, Department of Neurosurgery, Clinical Neurosciences Center, University of Utah, 175 N Medical Dr. East, Salt Lake City, UT 84132. email: neuropub@hsc.utah.edu. 